\title{
The Cambridge phenomenon
}

from Richard Pearson

\section{As science parks continue to proliferate throughout the United Kingdom, it remains difficult to define the ingredients for success}

HigH technology and small businesses are seen as two essential routes to job creation in both Europe and North America. As a result, policy makers are looking for the key to unlock such job creation potential by stimulating the development and utilization of high technology, and by aiding and encouraging the would-be entrepreneur. For some, science parks are the magic catalyst which draws the two phenomena together. By observing the success of Silicon Valley in the United States, which itself was spawned by Stanford University via its science park, and now has 200,000 jobs, every higher education institution and local authority in the United Kingdom now has plans or ideas for developing its own version of a science park. For those thinking on a grander scale, then the replication of Silicon Valley itself, for example as in Silicon Glen in Scotland, which has developed as a result of public policy initiatives and now has 40,000 jobs, or the M4 sunbelt in England where growth has been more spontaneous, is the ideal translation from high technology to job creation. In the United Kingdom the concept of the science park is taking many different forms, ranging from, at one extreme, the re-labelling of a high quality industrial estate in pleasant surroundings, to the park located adjacent to and on land owned by a higher education institution. There are now over 40 such initiatives under way.

The Cambridge Science Park, formed in 1973, and owned and developed by the University of Cambridge, has been one of the UK pioneers. In addition, the area has also spawned the 'Cambridge phenomenon', the apparently spontaneous emergence of a cluster of high technology companies along the lines of Silicon Valley. As well as being the home for Sinclair and Acorn, two of the biggest microcomputer companies in the world, the area contains over $\mathbf{3 0 0}$ other high technology companies, employing nearly 14,000 people between them and accounting for one in six local jobs. Their total turnover in 1984 has been estimated at $£ 890$ million ${ }^{\prime}$. While the first high technology company to come out of Cambridge University can be traced back to 1881 , when Cambridge Scientific Instrument Company was formed by Charles Darwin's son to manufacture scientific equipment for the university, the Cambridge phenonemon can be said to have really taken off some 100 years later. Over the past 20 years one new company has been established in the area every month, with peak rates of establishment occurring in 1978, 1981 and 1983 when over 2 per month were being established (Fig.1).

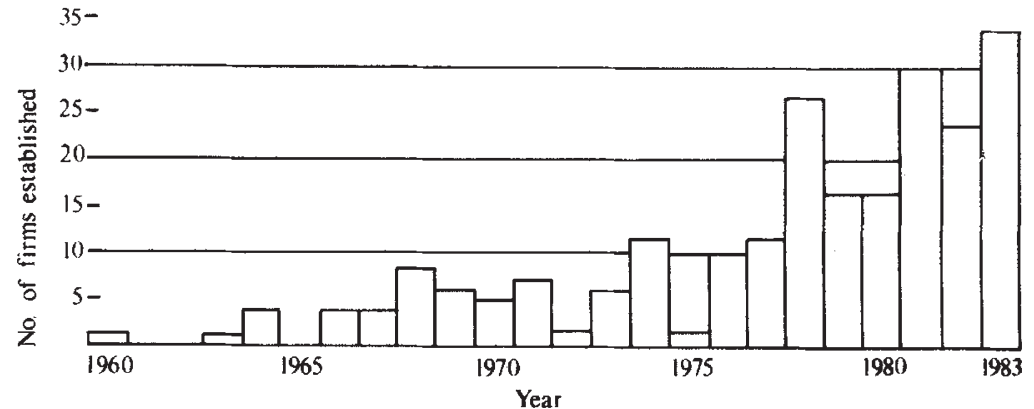

Fig.1 Dates of establishment of companies in the Cambridge area, as surveyed in ref.1.

Three quarters of these companies are new independent enterprises with the balance being made up of new branches of existing UK or overseas firms, or companies moving into the area. There is a high preponderance of very small companies in the total, one in three having five or fewer employees or an annual turnover of under $£ 400,000$. Electronics and computer hardware are the dominant business activities, but there is also a strong representation in biotechnology. A significant proportion of the companies' activities centre on research, design and development and consultancy.

The origins of the vast majority of these companies can be linked to the university, but only in a few cases, one in six, have they been formed by people coming straight from the university. For the majority it is because key staff have left one local company to start their own business in the area. This interconnection between companies, together with associated mobility of professional staff between companies, is seen as one of the great strengths and ingredients for success in both the formal settings of science parks, where the flows are expected to be between the educational establishment and industry, and in the 'Silicon Valleys', where it is between the companies involved. An additional asset of an area like Cambridge is the social network.

A distinguishing feature of high technology companies is the high qualification profiles of their workforces, a factor reinforced by the separation of manufacturing facilities to distant, and often offshore locations. In the Cambridge case, one in three of the staff in the companies were either managers or professional scientists and engineers, with the most recently formed companies having over half their staff in these categories. While shortages of such people are operating as a constraint in many locations, Cambridge does not seem to be suffering too badly. In part this is a result of the large supply of professionally trained graduates being produced by the university, but also the attractive location is an attraction to would-be migrants.

For many, the whole idea of a science park is that of the interplay of ideas between higher education institutions and local companies. In the Cambridge case, a study in $1983^{2}$ showed that there were surprisingly few formal linkages between the companies on the park, and that companies located elsewhere in the area were just as likely to have research contracts, consultancies and teaching commitments with the university. Such linkages would seem to find more expression through informal social contacts, ease of recruitment, and a 'halo' effect which stimulates action and change by example, rather than simply as a result of close physical proximity.

What, then, are the implications for other locations seeking to encourage new high technology firms? The first is that Cambridge has many special features which are unlikely to be repeated in many other areas. The second is that such developments take time, the Cambridge phenomenon had its beginnings many decades ago, with the science park having taken over 10 years to come to full fruition, and the park itself is only one small part of the process. Finally, if US experience is anything to go by, for every success, there will be a series of still-born or struggling parks. Science parks and high technology 'clusters' may have emerged quickly in the fashion stakes; the rewards for the successful will, however, come over a much longer time span, and while initiatives by public agencies can aid this process, 'natural' advantages will be just as important, and many of these are still not well understood

Richard Pearson is at the Institute of Manpower Studies, Mantell Buildings, University of Sussex, Brighton BNI $9 R F, U K$.

\footnotetext{
1. The Cambridge Phenomenon (Seagal, Quince and Partners, Cambridge 1985).

2. Moore, B. \& Spires, R. The Experience of the Cambridge Science Park (OECD, Paris, 1983).
} 